\title{
ALFABETIZAÇÃO DE CRIANÇAS COM DEFICIÊNCIA E REDUÇÃO DAS DESIGUALDADES NO ÂMBITO DO PACTO NACIONAL PELA ALFABETIZAÇÃO NA IDADE CERTA
}

\author{
Elci Schroeder Lucachinski* \\ Celso Francisco Tondin**
}

\begin{abstract}
RESUMO
A pesquisa objetivou analisar a relação entre alfabetização e redução das desigualdades escolares e sociais no que tange à orientação da prática pedagógica com alunos com deficiência, no âmbito da formação proporcionada pelo Pacto Nacional pela Alfabetização na Idade Certa (PNAIC). Trata-se de estudo de caso realizado na rede municipal de ensino de Chapecó-SC, com base em consulta a documentos e realização de entrevistas semiestruturadas com professoras participantes desse programa. Os dados foram tratados a partir da análise de conteúdo temática, aliada à hermenêutica dialética. Os documentos orientam a alfabetização desses alunos à medida que preconizam o atendimento das necessidades educacionais, compreendidas como diversidade e diferença, de todos os alunos. Para as professoras, a alfabetização contribui para a redução das desigualdades, porém há diferenças nos modos de compreendê-las. A maioria delas entende que as desigualdades decorrem dos próprios indivíduos e, no caso da deficiência, da condição biológica; e algumas delas referem a participação do contexto escolar e social na construção delas, embora isso não seja feito de um modo crítico. Apontamos a formação de professores integralmente orientada, com base na teoria histórico-cultural, como estratégia de redimensionamento da prática pedagógica do professor alfabetizador em direção à inclusão escolar de todos os alunos.
\end{abstract}

Palavras-chave: Deficiência. Alfabetização. PNAIC. Desigualdades. Diversidade.

\section{ABSTRACT \\ LITERACY OF CHILDREN WITH DISABILITIES AND REDUCTION OF INEQUALITIES IN THE NATIONAL PACT FOR LITERACY IN THE RIGHT AGE}

The research aimed to analyze the relationship between literacy and decrease of educational and social inequalities regarding the orientation of teaching practice with students with disabilities, in the formation provided by the National Pact for Literacy in the Right Age (PNAIC). It is a case study performed in public schools in Chapecó,

* Mestra em Educação pela Universidade Comunitária da Região de Chapecó (Unochapecó). Professora da Rede Municipal de Educação de Chapecó-SC. Membro do Grupo de Pesquisa Desigualdades Sociais, Diversidades Socioculturais e Práticas Educativas (Unochapecó). elci@unochapeco.edu.br

** Doutor em Psicologia pela Universidade Comunitária da Região de Chapecó (Unochapecó). Membro do Grupo de Pesquisa Desigualdades Sociais, Diversidades Socioculturais e Práticas Educativas (Unochapecó). tondin@unochapeco.edu.br 
in the state of Santa Catarina, based on the review of documents and semi-structured interviews with participating teachers in this program. The data were analyzed from the thematic content analysis, combined with the dialectic hermeneutics. The documents guide the literacy of these students while prescribe the attendance to the educational needs, understood as diversity and difference, of all students. For teachers, literacy contributes to the reduction of inequalities, but there are differences in modes of understanding them. Most of them understand that inequalities result from the individuals themselves and, in the case of disability, from the biological condition; and some of them refer to the participation of educational and social context in the construction of them, although this is not done in a critical mode. We point the teachers formation fully oriented, based on the historical-cultural theory, as resizing strategy of pedagogical practice of literacy teacher towards the school inclusion of all students.

Keywords: Disabilities. Literacy. PNAIC. Inequalities. Diversity.

\section{RESUMEN}

\section{ALFABETIZACIÓN DE NIÑOS CON DEFICIENCIA Y REDUCCIÓN DE DESIGUALDADES EN EL ÁMBITO DEL PACTO NACIONAL POR LA ALFABETIZACIÓN EN LA EDAD CORRECTA.}

La investigación tuvo como objetivo analizar la relación entre la alfabetización y reducción de las desigualdades escolares y sociales con respecto a la orientación de la práctica pedagógica con los estudiantes con discapacidad, en el ámbito de formación proporcionada por el Pacto Nacional por la Alfabetización en la Edad Correcta (PNAIC). Se trata de un estudio de caso en la red de escuelas públicas en Chapecó, Santa Catarina, basado en consulta a documentos y realización de entrevistas semi-estructuradas con profesores que participan en este programa. Los datos fueron analizados a partir del contenido temático, combinado con la hermenéutica dialéctica. Los documentos guían la alfabetización de estos estudiantes a medida que preconizan la atención de las necesidades educativas, entendidas como diversidad y la diferencia, de todos los estudiantes. Para las profesoras, la alfabetización contribuye a la reducción de las desigualdades, sin embargo hay diferencias en las formas de comprenderlas. La mayoría de ellas entienden que las desigualdades se deben a los propios individuos y, en el caso de la discapacidad, de la condición biológica; y algunas de ellas se refieren a la participación de contexto escolar y social en la construcción de ellas, aun que esto no se hace de una manera crítica. Señalamos la formación de maestros integralmente orientada, con base en la teoría histórico-cultural como estrategia de cambio de la práctica pedagógica del profesor alfabetizador en dirección a la inclusión escolar de todos los estudiantes.

Palabras claves: Discapacidades. Alfabetización. PNAIC. Desigualdades. Diversidad.

\section{Introdução}

No cotidiano da comunidade escolar, verifica-se que o avanço do ensino na área da alfabetização é uma das questões cruciais a serem enfrentadas para se avançar na qualidade da educação. E quando se trata de inclusão dos alunos com deficiência, as manifestações dos professores são preocupantes, principalmente no que se refere às dificuldades e aos limites que vivenciam no atendimento às necessidades e ao respeito às peculiaridades desses alunos. Diante dessa realidade, políticas educacionais estão sendo implantadas ou reestruturadas, em nosso país, com vistas à garantia de uma educação inclusiva. 
Se por um lado o ideário da inclusão escolar é um dos fundamentos da sociedade democrática, por outro é necessário superar a visão ingênua sobre o uso desse termo, pois ele é polissêmico, visto que veicula diferentes concepções políticas, epistemológicas e ideológicas que nem sempre vão ao encontro da inclusão como efetivação de ações educativas que considerem as diversidades e as diferenças como enriquecedoras do processo ensino-aprendizagem, possibilitando assim aprendizagem como direito de todos os alunos. Desse modo, os espaços escolares necessitam rever constantemente sua organização, currículos e relações no sentido de efetivar uma concepção de educação em que a heterogeneidade, as diferenças nos/dos alunos se façam indispensáveis para a construção do conhecimento. Nesse processo, toda a sociedade também precisa rever sua organização a fim de efetivar o direito à inclusão.

Diante dessa premissa, o governo federal afirma disponibilizar programas que objetivam a inclusão escolar, promovendo assim a redução das desigualdades sociais, através de uma educação pública de qualidade para todos. Um desses programas é o Pacto Nacional pela Alfabetização na Idade Certa (PNAIC), que objetiva que as crianças brasileiras estejam alfabetizadas até os oito anos de idade, ao fim do terceiro ano do ensino fundamental. $\mathrm{O}$ principal eixo do Pacto é a formação de professores alfabetizadores, a quem são oportunizados cursos presenciais, nos municípios onde residem, com duração de dois anos. No primeiro ano, em 2013, foi enfatizada a Língua Portuguesa e no segundo, em 2014, a Matemática.

O Plano de Desenvolvimento da Educação (PDE) (BRASIL, 2007) e o Plano Nacional de Educação (PNE) (BRASIL, 2014b) abordam o tema da alfabetização. A meta cinco do PNE prevê "Alfabetizar todas as crianças, no máximo, até o final do $3^{\circ}$ (terceiro) ano do ensino fundamental." Para que isso aconteça foram elencadas várias estratégias, sendo que a 5.7 refere: "Apoiar a alfabetização das pessoas com deficiência, considerando as suas especificidades, inclusive a alfabetização bilíngue de pessoas surdas, sem estabelecimento de terminalidade temporal." (BRASIL, 2014b).

A implementação do PNAIC tem provocado discussões no que tange à prática pedagógica em sala de aula, evidenciando-se dificuldades, incertezas e angústias quanto ao compromisso de alfabetizarem todas as crianças na "idade certa", o que se assevera quando se trata dos alunos com deficiência. Esse fato se apresenta como questão importante tanto para os gestores e profissionais que trabalham com as políticas educacionais, quanto para o meio acadêmico que as investigam, no sentido que afirma Arroyo (2010, p. 1.382): “[...] os estudos, as pesquisas e os debates sobre a relação entre educação e desigualdades têm sido um dos campos mais fecundos e instigantes no pensamento educacional progressista e na formulação e gestão, na análise e avaliação de políticas educativas."

Dessa maneira, o presente estudo se caracteriza como atual e relevante devido ao fato de que, no discurso oficial, o PNAIC, a exemplo de outras políticas educacionais, foi elaborado e concretizado na tentativa de reduzir as desigualdades escolares e sociais. Na fala de lançamento desse programa, a presidenta Dilma Rousseff refere o papel da alfabetização na alteração das desigualdades existentes em nosso país e destaca que a procura por alternativas para a mudança dessa realidade tem ocupado lugar de destaque nas políticas públicas educacionais (SOUSA; MEIRA, 2013).

Arroyo (2010) faz uma reflexão nessa direção, afirmando que as desigualdades são geradas por processos de produção e reprodução estabelecidos na sociedade, indo, portanto, além das desigualdades intraescolares, o que demanda, assim, políticas sociais, entre elas as de educação, que provoquem mudanças nas estruturas escolares e sociais. Desta forma, é imprescindível problematizar, discutir as desigualdades, estabelecendo relações com a prática pedagógica para alunos com deficiência.

Diante disso, este artigo, decorrente de dissertação de Mestrado em Educação (LUCACHINSKI, 2015), tem como objetivo analisar a relação entre alfabetização e redução das desigualdades escolares e sociais no que tange à orientação da prática alfabetizadora de alunos com deficiência, no âmbito da formação continuada proporcionada pelo PNAIC na rede municipal de educação de Chapecó, no estado de Santa Catarina.

A busca em base de dados revela que pesquisas anteriores não abordaram esse programa, o que se pode atribuir ao fato da sua implantação ter-se 
iniciado recentemente. No entanto, destaca-se a investigação realizada por Aureliano (2012), cuja dissertação intitulada O Programa Pró-letramento e a formação de alfabetizadores: repercussões nas concepções e práticas de professores cursistas objetivou investigar as repercussões deste programa nas concepções e práticas de professoras participantes. Importante salientar que o Pró-Letramento é um dos precursores do PNAIC, porém a pesquisa citada não tratou da formação para a alfabetização de crianças com deficiência. Ou seja, há lacunas a serem preenchidas no que se refere a estudos sobre as relações entre a formação continuada proporcionada pelo PNAIC no país e as orientações quanto à alfabetização de alunos com deficiência.

Esta investigação, de caráter qualitativo, caracteriza-se como estudo de caso, nos termos de Lüdke e André (1986, p. 21), que "[...] implica que o objeto de estudo seja examinado como único, uma representação singular da realidade, realidade esta, multidimensional e historicamente situada". A pesquisa de campo aconteceu após aprovação do Comitê de Ética em Pesquisa Envolvendo Seres Humanos da Universidade Comunitária da Região de Chapecó (Unochapecó), sob parecer consubstanciado n. 143/14. Os dados foram obtidos mediante consulta a documentos do programa e realização de entrevistas semiestruturadas com professoras participantes dessa formação.

Os documentos consultados foram os cadernos gerais do programa: Currículo na alfabetização: concepções e princípios (BRASIL, 2012b), Formação de professores no Pacto Nacional pela Alfabetização na Idade Certa (BRASIL, 2012c) e Formação do professor alfabetizador: caderno de apresentação (BRASIL, 2012d); e cadernos específicos que abordam a alfabetização de crianças com deficiência: Caderno de Educação Especial: a alfabetização de crianças com deficiência: uma proposta inclusiva (BRASIL, 2012a) e Caderno de Educação Inclusiva: alfabetização matemática (BRASIL, 2014a).

As entrevistas foram realizadas com 13 professoras participantes da formação no referido município, o que representa $100 \%$ das que informaram atuar com alunos com deficiência em 2013 ou 2014. As perguntas giraram em torno de duas questões-guia: como são contempladas as orientações sobre a alfabetização dos alunos com deficiência nos documentos oficiais da formação continuada proposta pelo PNAIC? A alfabetização, no âmbito do PNAIC, contribui para a redução das desigualdades escolares e sociais?

Os dados foram tratados a partir da análise de conteúdo temática, aliada à hermenêutica dialética, conforme Minayo (2008). Dessa forma, eles foram organizados em torno de dois núcleos de sentido: orientação dos documentos sobre a prática alfabetizadora de crianças com deficiência e concepções das professoras sobre a relação entre alfabetização e redução das desigualdades. Para isso foram entrecruzados os dados coletados nas entrevistas e nos documentos, dialogando com os fundamentos da teoria histórico-cultural, que filia-se aos pressupostos epistemológicos do materialismo histórico dialético. Como nos dizem Veronezi, Damasceno e Fernandes (2005, p. 539), o referencial teórico histórico-cultural compreende:

[...] a relação entre sujeito e objeto no processo de construção do conhecimento, no qual o sujeito do conhecimento não é apenas passivo, regulado por forças externas que o vão moldando e nem é somente ativo, regulado por forças internas, o sujeito do conhecimento é interativo.

Esta pesquisa se inscreve em um leque de estudos que tem analisado políticas educacionais implementadas em diversos contextos locais, nacionais e internacionais, a partir de uma perspectiva de “análise crítica de políticas específicas", cuja opção é uma das formas de abordá-las, como apontam Bell e Stevenson (2006 apud BALL; MAINARDES, 2011, p. 11).

O termo crítico sinaliza que o objetivo dessas pesquisas é

[...] compreender a essência das políticas investigadas, com o cuidado de analisá-las de modo aprofundado, evitando-se toda e qualquer forma de legitimação; analisá-las de uma perspectiva de totalidade, estabelecendo vínculos com o contexto [...] econômico, político e social, e analisar as relações das políticas com a justiça social. (BALL; MAINARDES, 2011, p. 13).

Sendo assim, a contribuição pretendida neste artigo é problematizar a formação proporcionada pelo PNAIC com foco nos processos de produção/ 
reprodução/superação das desigualdades em sua relação com a deficiência e interconexões entre micro e macrocontextos, na perspectiva da construção da justiça social, que tem como componente imprescindível a diversidade humana.

\section{Resultados e discussão}

Alfabetização de crianças com deficiência: o que dizem os documentos?

Ao longo da história, o conceito e sentidos atribuídos à alfabetização têm mudado. Soares (2003, p. 15) sugere que ao ensinar a ler e escrever o professor o faça no contexto do letramento e ressalta a necessidade de distinguir alfabetização de letramento:

[...] a necessidade de estabelecer a distinção entre o que mais propriamente se denomina letramento, de que são muitas as facetas - imersão das crianças na cultura escrita, participação em experiências variadas com leitura e a escrita, conhecimento e interação com os diferentes tipos e gêneros de material escrito -, e o que é propriamente a alfabetização, de que também são muitas as facetas - consciência fonológica e fonêmica, identificação das relações fonema-grafema, habilidades de codificação da língua escrita, conhecimento e reconhecimento dos processos de tradução da forma sonora da fala para a forma gráfica da escrita.

Assim, a autora define duas vias para o aluno entrar no mundo da leitura e escrita: uma delas se refere a aprender um conjunto de técnicas - a alfabetização - e aprender o uso dessas técnicas nas práticas sociais - o letramento -, que são processos simultâneos e interdependentes. A autora defende que tanto a alfabetização como o letramento são multifacetados, por isso exigem usos de métodos diferenciados. Desse modo, a especificidade de cada um exige "[...] conhecimentos, habilidades e competências específicos, que implicam formas de aprendizagem diferenciadas e, consequentemente, procedimentos diferenciados de ensino." (SOARES, 2003, p. 19). Sendo assim, a alfabetização compreendida a partir da perspectiva de letramento implica que se estabeleçam relações da escrita e da leitura com o cotidiano e as necessidades dos alunos, ou seja, não se trata apenas de uma tarefa escolar vazia de sentido, mas de uma prática sociocultural significativa.

Considerando os alunos com deficiência, retoma-se a Política Nacional de Educação Especial na Perspectiva de Educação Inclusiva, de 2008, que considera pessoa com deficiência, "[...] aquela que tem impeditivos de longo prazo, de natureza física, mental ou sensorial que, em interação com diversas barreiras, pode ter restringida sua participação plena e efetiva na escola e na sociedade." (BRASIL, 2010, p. 23). Esse conceito representa um avanço, pois concebe a deficiência não apenas como uma condição individual e biológica, mas social e cultural na medida em que ressalta a interação das pessoas com deficiência com barreiras que muitas vezes impedem a participação delas na escola e na sociedade em geral.

Entendido dessa forma, quando o conhecimento não está acessível aos alunos, criam-se obstáculos para a sua aprendizagem. Por isso, quando se trata da alfabetização de crianças com deficiência, não se concebe (ou não se deveria conceber) uma prática realizada à margem do processo desenvolvido por todos os alunos. Isso coloca o imperativo ético de que a escola possibilite uma educação inclusiva, visto que dificuldades de aprendizagem são muitas vezes explicadas com base em fatores orgânicos, eximindo-se as dimensões institucionais e sociais. Isto é, mesmo com os avanços significativos nas práticas sociais e especificamente na educação escolar de pessoas com deficiência na perspectiva de educação inclusiva, percebe-se que essas continuam sendo, frequentemente, marcadas por concepções que ressaltam a "incapacidade" e "anormalidade" delas.

A escola tem papel fundamental na superação desses estigmas, mas ela não está desvinculada da sociedade e, portanto, das práticas excludentes em um âmbito maior. Por isso, faz-se imprescindível uma análise mais ampla das estruturas sociais, as quais têm contribuído significativamente para a promoção das desigualdades que historicamente constituem a educação dos sujeitos com deficiência. Assim, a educação pode vir a contribuir para que a sociedade seja mais justa e menos excludente. Dessa reflexão emerge o questionamento: a educação escolar, especificamente a alfabetização, pode oportunizar práticas de ampliação da participação 
desses sujeitos na vida social e contribuir para a redução das desigualdades?

A consulta aos documentos do PNAIC possibilitou identificar as orientações pedagógicas acerca das peculiaridades da aprendizagem de crianças com deficiência. De fato, a inclusão delas é contemplada nos documentos do programa, o que já se explicita em um dos seus objetivos: "Compreender e desenvolver estratégias de inclusão de crianças com deficiência visual, auditiva, motora e intelectual, bem como crianças com distúrbios de aprendizagem no cotidiano da sala de aula." (BRASIL, 2012d, p. 31).

Esse objetivo se materializa em conteúdos previstos para serem trabalhados no processo de formação. Nas unidades um, quatro e sete são assim contemplados estudos sobre a inclusão de alunos com deficiência no processo de alfabetização:

01 (12 horas) Ementa: Concepções de alfabetização; currículo no ciclo de alfabetização; interdisciplinaridade; avaliação da alfabetização; inclusão como princípio fundamental do processo educativo. [...] 04 (12 horas de trabalho). Ementa: A sala de aula como ambiente alfabetizador: [...] estratégias de inclusão de crianças com deficiência visual, auditiva, motora e intelectual, bem como crianças com distúrbios de aprendizagem nas atividades planejadas. 07 (8 horas). Ementa: Avaliação; planejamento de estratégias de atendimento das crianças que não estejam progredindo conforme as definições dos conceitos e habilidades a serem dominados pelas crianças (direitos de aprendizagem); a inclusão das crianças com dificuldades de aprendizagem e crianças com necessidades educacionais especiais. (BRASIL, 2012d, p. 33, grifo nosso).

Nessas unidades, é enfatizada a proposição de atividades diversificadas para atender as particularidades dos alunos e abordada a necessidade de possibilitar estratégias de inclusão de crianças com deficiência. Também, no que se refere à avaliação da aprendizagem, é ressaltada a importância do planejamento de estratégias de atendimento para as "crianças com necessidades educacionais especiais" (BRASIL, 2012c, p. 33). Este termo, de acordo com a Declaração de Salamanca (1994), "[...] refere-se a todas aquelas crianças ou jovens cujas necessidades educacionais especiais se originam em função de deficiências ou dificuldades de aprendizagem." Sendo assim, é possível compreender que a formação do PNAIC foi planejada tendo como princípio a inclusão de todos os alunos, pois em consonância com o promulgado pela Declaração, as necessidades educacionais especiais não se referem apenas aos alunos com deficiência, mas a todos que necessitam provisória ou permanentemente de recursos para a acessibilidade ao conhecimento.

A partir dessa compreensão, constata-se que o Caderno de Educação Especial (BRASIL, 2012a) e o Caderno de Educação Inclusiva (BRASIL, 2014a) tratam especificamente sobre a acessibilidade ao conhecimento de alunos com deficiência física, visual, intelectual e auditiva, ressaltando e exemplificando os recursos, metodologias e mediações a partir das peculiaridades e necessidades de cada deficiência.

Ambos os cadernos enfatizam que a formação deveria orientar a prática alfabetizadora dos professores a partir de determinados objetivos. No Caderno de Educação Especial, que é de 2012, consta:

Compreender e desenvolver estratégias de inclusão de crianças com deficiência visual, auditiva, motora e intelectual, no cotidiano da sala de aula; criar um ambiente alfabetizador, que favoreça a aprendizagem das crianças em espaços comuns; conhecer a importância do uso de jogos e brincadeiras no processo de apropriação do sistema alfabético de escrita, analisando jogos e planejando aulas em que os jogos sejam inclusivos, aplicados como recursos didáticos. (BRASIL, 2012a, p. 5).

De acordo com esses objetivos, verifica-se que o programa, na sua constituição, contemplou estratégias de ensino para orientar a prática dos professores alfabetizadores que atuam com alunos com as referidas deficiências, no entanto, no primeiro caderno não foi contemplada a atuação com alunos com transtornos globais do desenvolvimento e altas habilidades, que também estão nas escolas e demandam dos professores conhecimentos específicos para trabalhar com este público, que é contemplado na Política Nacional de Educação Especial na Perspectiva da Educação Inclusiva (BRASIL, 2008).

Por sua vez, no Caderno de Educação Inclusiva, publicado em 2014, está previsto: 
Ampliar conhecimentos sobre aspectos legais referentes à Educação Especial na perspectiva da Educação Inclusiva; aprofundar conhecimentos sobre encaminhamentos destinados aos alunos que fazem parte do público-alvo da Educação Especial; ampliar conhecimentos sobre espaços de aprendizagem dos alunos com deficiência, transtornos globais do desenvolvimento e altas habilidades/superdotação. No contexto da inclusão escolar, ou seja, o trabalho da escola comum articulada com o Atendimento Educacional Especializado (AEE); compreender a importância de um trabalho considerando as diferenças dos alunos com ações voltadas a promover o acesso, a participação e a aprendizagem dos mesmos; sugerir práticas pedagógicas de alfabetização matemática para alunos com necessidades específicas. (BRASIL, 2014a, p. 5).

Constata-se que esse caderno ampliou as discussões, contemplando a atuação com todos os alunos que são público-alvo da educação especial. Outro avanço dele em relação ao caderno de 2012 se refere ao fato de que ao abordar cada deficiência são explicitadas as condições de funcionamento do Atendimento Educacional Especializado (AEE) em Sala de Recurso Multifuncional (SRM), ${ }^{1}$ enfatizando a articulação com os profissionais do ensino regular.

Vygotsky (1995, p. 3) pondera que “[...], el niño com deficiencias representa um tipo peculiar, cualitativamente distinto de desarrollo". Por isso, serão abordados os recursos e metodologias utilizados com os alunos com deficiência física, intelectual, visual e auditiva no contexto de sala de aula regular e a articulação com o AEE. Para isso é importante ressaltar o que diz o caderno de 2014: "Conhecer os recursos e funcionamento do AEE é poder contar com maiores possibilidades de trabalho para a prática docente em direção a superar as barreiras à aprendizagem." (BRASIL, 2014a, p. 22).

\section{Deficiência física}

No caderno de 2012, o texto escrito por Cavalcante (2012, p. 10) caracteriza a "deficiência

1 Tem como objetivo o AEE realizado em SRM "[...] identificar, elaborar e organizar recursos pedagógicos e de acessibilidade que eliminem as barreiras [...]" (BRASIL, 2010, p. 21) para que os alunos público-alvo da educação especial acessem os conteúdos curriculares do ensino comum. As atividades desenvolvidas acontecem no contraturno da classe comum. motora" (no caderno de 2014 é denominada "deficiência física"): “[...] pelos impedimentos nos movimentos e na coordenação de membros e/ou de cabeça, em que a pessoa necessitará de adaptações que garantam a acessibilidade motora." Pode-se afirmar que, nesse sentido, o acesso aos espaços físicos e aos recursos necessários à particularidade apresentada pelo aluno é imprescindível para o processo ensino-aprendizagem. Por isso, o professor e, se necessário, outros profissionais, como terapeuta educacional e fisioterapeuta, necessitam realizar uma avaliação diagnóstica para planejar e elaborar em conjunto de materiais e/ou recursos que possibilitem acessibilidade nas atividades desenvolvidas na escola e fora dela.

Em ambos os cadernos as discussões proporcionadas sobre a deficiência física focalizaram os alunos com paralisia cerebral por entender que esta é a causa mais frequente desta deficiência e "[...] é definida como uma desordem do movimento e da postura em decorrência de uma lesão, não progressiva, do cérebro ainda em desenvolvimento." (TELES; NASCIMENTO, 2005 apud CAVALCANTE, 2012, p. 10).

A partir de uma avaliação específica sobre as necessidades de recursos para acessibilidade do aluno na escola (conhecimentos e espaço físico) e fora dela, o professor da SRM e outros profissionais podem indicar recursos de tecnologias acessíveis.

Duas questões tornam-se centrais nesse tópico: (a) a identificação das peculiaridades educacionais de cada estudante é fundamental para a escolha das estratégias e dos recursos didáticos e pedagógicos; (b) a promoção de acessibilidade nem sempre depende de alta Tecnologia Assistiva (área do conhecimento e de atuação que desenvolve serviços, recursos e estratégias que auxiliam na promoção de acessibilidade às pessoas com deficiência), já que o/a professor(a) pode utilizar de sua criatividade para realizá-las (CAVALCANTE, 2012).

Além de indicar um dos principais recursos de tecnologia para eliminar a barreira na comunicação - a Comunicação Alternativa e Suplementar (CAS) -, a autora também salienta os recursos disponíveis na escola e a possibilidade dos professores confeccionarem materiais didáticos.

Os autores dos textos do Caderno de Educação Inclusiva, que explanam sobre os recursos de tec- 
nologia assistiva, utilizam o termo Comunicação Aumentativa e Alternativa (CAA). Destacam que esses recursos tecnológicos possibilitam a interação e comunicação de pessoas "[ [...] sem fala ou sem escrita funcional, ou em defasagem entre sua necessidade comunicativa em falar e/ou escrever." (BRASIL, 2014a, p. 23).

Nesse caderno também é ressaltado que é fundamental para a aprendizagem dos alunos com deficiência intelectual que o trabalho da SRM enfatize o desenvolvimento de atividades considerando situações-problema elencadas a partir dos conhecimentos prévios do aluno. É destacado o uso variado de recursos pedagógicos, os quais podem contribuir para a aprendizagem de conceitos, não apenas para os alunos com deficiência intelectual, mas para todos.

Quanto à alfabetização, é ressaltado em ambos os cadernos que o professor precisa ressignificar a sua prática para atender as particularidades dos alunos, e que não existem fórmulas e nem receitas prontas. Muitas alternativas de adaptação podem ser disponibilizadas para o aluno acessar a leitura e a escrita, mesmo com a falta de coordenação manual ou impedimentos de locomoção, visto que essa aprendizagem requer trabalho conceitual e não mecânico.

Essas considerações se aproximam das proposições da teoria histórico-cultural, pois ela entende que a aprendizagem é decorrente da trans/formação de conceitos, por isso é necessário proporcionar estratégias de ensino que intervenham por meio de instrumentos materiais e simbólicos, no processo de elaboração conceitual, mediante processos de operações intelectuais de análise, abstração, generalização e síntese, pois "[...] a formação de conceitos surge sempre no processo de solução de algum problema que se coloca para o pensamento" (VYGOTSKY, 2009, p. 237) e não na proposição de atividades mecânicas, as quais não correspondem às necessidades essenciais para a aprendizagem, assim como pressupõe a alfabetização na perspectiva de letramento.

Os autores dos textos do Caderno de Educação Especial sugerem como possibilidades de escrita a prancha de letras para o aluno apontar uma a uma, enquanto outra pessoa registra a produção. Quando o aluno não consegue apontar, alguém faz uma varredura até que o aluno sinalize: piscar, emitir som, dentre outros (BRASIL, 2012a).

\section{Deficiência intelectual}

O processo de alfabetização das crianças com deficiência intelectual, segundo Cavalcante (2012), acontece como a das demais crianças, porém deve-se levar em conta que as crianças apresentam um ritmo de aprendizagem diferenciado e as peculiaridades dos alunos com deficiência intelectual devem ser contempladas no planejamento geral do trabalho com a turma em que estudam.

A CAS é sugerida para facilitar a comunicação e a aprendizagem, "[...] caso não haja o avanço na construção de sentidos via linguagem oral, eles podem ser construídos através de ferramentas de CAS." (CAVALCANTE, 2012, p. 17). No entanto, a autora também enfatiza a necessidade do professor planejar materiais didáticos que propiciem a participação dos alunos nas atividades escolares.

Assim, a deficiência intelectual não é uma condição estática, nem um traço pessoal, não podendo ser vista somente pelos impedimentos. Ela deve ser compreendida dentro de uma abordagem ecológica que considere o funcionamento da pessoa na interação com o mundo em que vive, observando as oportunidades e o apoio recebidos ao longo da vida. O trabalho do(a) professor(a) deve priorizar o desenvolvimento intelectual e a autonomia dos seus alunos com deficiência intelectual, não enfatizando atividades mecânicas, e sim o desenvolvimento das funções psicológicas superiores com aprendizagens significativas, conforme defende Vygotsky (CAVALCANTE, 2012).

Os autores que escreveram o texto sobre deficiência intelectual no caderno de 2014 ressaltam que a deficiência intelectual "[...] passa a ser compreendida como uma interação entre o funcionamento intelectual e suas relações com o contexto social." (BRASIL, 2014a, p. 27). Dessa forma, as limitações do contexto social passam a ser consideradas como obstáculo à aprendizagem e ao desenvolvimento das pessoas com deficiência intelectual, necessitando esses contextos ofertarem apoios necessários à inclusão dessas pessoas nos espaços escolares e na sociedade como um todo. 
Os textos dos referidos cadernos permitem aos professores uma reflexão sobre as suas práticas, a fim de reconhecerem os limites no atendimento escolar às diferenças dos alunos que têm se traduzido em dificuldades no processo de inclusão deles no ensino comum:

Você já parou para pensar se as condições de aprendizagem do seu aluno são favoráveis? Seu aluno está sendo incluído nas atividades pedagógicas e no seu planejamento diário? Você conhece e considera suas características individuais? Está avaliando adequadamente? Se esses fatores não tiverem sendo respeitados, então seu aluno não vai aprender, mas não porque ele não tem condições, e sim porque seus direitos à aprendizagem estão sendo negados. Em outros termos, você estará negando ao seu aluno a inclusão, restando-lhe apenas as condições de inserido no universo da sala de aula, mas excluído dos processos que nela ocorrem, para que todos tenham garantidos os direitos de aprendizagem. (CAVALCANTE, 2012, p. 17).

Essas discussões nos reportam à reflexão sobre a diferença entre inclusão e integração, termos tratados, muitas vezes, como sinônimos em bibliografias, na escola e na sociedade em geral. Como bem exemplificado pela autora, quando não é propiciado aos alunos acesso ao conhecimento e não é contemplada a participação ativa deles nas ações educativas, somente acontece a integração, ou seja, eles estarão inseridos no ambiente escolar, no entanto, excluídos do processo de interação e mediação que possibilita a aprendizagem.

\section{Deficiência visual}

Quanto às estratégias de alfabetização das pessoas com deficiência visual, é abordada primeiramente a compreensão da sua classificação. Segundo Domingues (2010 apud SEAL, 2012, p. 21), a baixa visão "[...] é a diminuição do campo visual e a cegueira é caracterizada pela ausência da visão". Contribuindo com os autores, pode-se dizer que a baixa visão se caracteriza quando as pessoas não conseguem enxergar caracteres em tinta ou objetos, pessoas, dentre outros, necessitando de recursos ópticos, não ópticos e outras tecnologias para desenvolver atividades que exigem visão. Acrescenta-se ainda ao conceito citado a necessi- dade de verificação não somente do campo visual, mas também da acuidade visual como requisitos para a identificação da deficiência visual. Já a cegueira está presente quando a pessoa não consegue enxergar nada ou apenas luzes e vultos, necessitando do Sistema Braille para a leitura e a escrita, bem como de outros recursos que possibilitem a sua interação com o mundo.

Nesse sentido, o processo de alfabetização terá êxito desde que sejam oferecidos aos alunos os materiais e recursos de acessibilidade, sem esquecer-se da importância da interação deles com crianças de sua idade e mediações qualificadas. Concorda-se com Seal (2012, p. 22) quando, em seu texto no Caderno de Educação Especial, afirma que a capacidade e potencialidade das pessoas com deficiência visual dependerá das oportunidades e condições oferecidas:

Ela pode ser olhada e entendida como pessoas diferentes, sim, enquanto aparência, enquanto forma de comunicação, enquanto indivíduo, mas iguais às demais pessoas, enquanto capacidade produtiva e relacional, com enorme potencial a ser desenvolvido e com possibilidades de desenvolver vários trabalhos e serviços de que a sociedade precise desde que lhes sejam oferecidas oportunidades e condições necessárias.

A autora sugere a aplicação do teste de Snellen para identificar os alunos com deficiência visual:

Esse procedimento pode colaborar com o trabalho do/a professor/a alfabetizador à medida que os alunos identificados com deficiência visual são encaminhados aos especialistas para que tenham acompanhamento médico-oftalmológico que pode vir a contribuir em alguns casos. Além disso, torna-se possível ao docente prever estratégias de ensino da linguagem acessíveis aos alunos com cegueira ou baixa visão. (SEAL, 2012, p. 22).

Visando contribuir com os postulados da autora, é importante dizer que, no contexto escolar, o teste de Snellen pode ser utilizado para a realização de uma triagem e os alunos que demonstrarem dificuldade visual poderão ser encaminhados ao médico oftalmologista. Porém, não se pode esquecer da importância e necessidade da avaliação funcional da visão para o processo de alfabetização. Através de uma investigação da funcionalidade visual, 
pode-se elaborar e propor recursos e estratégias de acessibilidade ao currículo e ao ambiente escolar. Como exemplos, podemos citar: tamanho de letras; distância que o aluno demonstra enxergar melhor do quadro; se necessita de ambientes bem iluminados ou ao contrário; se necessita de recurso para aproximar o material a ser lido, dentre outros. A avaliação funcional da visão torna-se importante também para a própria criança e seus familiares conhecerem a patologia que ocasionou a deficiência visual, bem como os recursos que podem ser utilizados no dia a dia para melhorar o seu desempenho visual.

É necessário considerar que o processo de alfabetização de crianças com deficiência visual, como o de qualquer outra criança, é embasado pelas construções conceituais e não apenas pela decodificação das letras. Por isso,

É relevante pensar que é preciso inserir as crianças com deficiência visual em situações em que a leitura e a escrita sejam utilizadas de forma significativa e de preferência em situações reais, adequadas ao gênero textual e ao contexto de utilização. Se para as crianças videntes as ilustrações passam a ser mais um atrativo, para as com deficiência visual o uso de descrições ou objetos/situações que possam dar vida às situações da leitura e escrita precisa ser promovido. (SEAL, 2012, p. 22).

Assim, a escola necessita dispor de materiais e recursos que possibilitem o processo para alfabetização, tais como: objetos em miniaturas, ampliação de textos, bengala, essências de cheiros diversos, gravador, reglete, punção, folhas mais duras como a de 40 ou $60 \mathrm{k}$, bem como:

[...] soroban (ábaco para o ensino do sistema numérico), ferramentas de comunicação, com sintetizadores de voz que possibilitam a leitura e a escritura pelo computador, lupas manuais, eletrônicas, plano inclinado, jogos com letras e palavras em tipo ampliado, cores contrastantes e sua representação em braile. Além disso, no AEE, o aluno cego deve receber o ensino do braile, noções de orientação e mobilidade e de atividades de vida autônoma e social. É preciso, contudo, lembrar que a utilização desses recursos não substitui o currículo e as aulas regulares. (SEAL, 2012, p. 25).

Os alunos com deficiência visual necessitam apenas de recursos e estratégias diferenciadas, ou seja, o professor deve proporcionar-lhes os mesmos conteúdos e atividades que lhes são de direito, como dos demais colegas de turma.

\section{Deficiência auditiva}

O processo de alfabetização da pessoa com deficiência auditiva ou com surdez, ${ }^{2}$ de acordo com Mourão e Souza (2012, p. 28) “[...] é considerado como um grande desafio na educação desses sujeitos." No entanto, o professor não pode considerar a deficiência auditiva ou a surdez como impedimento para a alfabetização.

Qual é o ponto de partida na alfabetização da criança surda? O ponto de partida é esse sujeito ter uma língua que lhe sirva de arcabouço para pensar, hipotetizar, por isso devemos começar pela língua de sinais, para chegarmos ao ensino de língua portuguesa na sua modalidade escrita, lembrando ainda que o ensino de língua portuguesa na sua modalidade oral deve ser uma oferta obrigatória na educação básica, resguardando o direito de opção da família e do aluno (MOURÃO; SOUZA, 2012).

$\mathrm{O}$ texto apresenta sugestões importantes que devem ser consideradas na comunicação com esses alunos no sentido de que sua alfabetização

[...] requer pensar em possibilitar o acesso à construção do conhecimento por meio da língua de sinais, e para isso são necessários professores fluentes na Libras. Requerendo também o ensino da LP [Língua Portuguesa] embasado no aprendizado de uma segunda língua, onde os sujeitos estão ou estarão vivendo o processo de interferência entre idiomas de convivência, fenômeno que chamamos de 'interlíngua', momento onde é fundamental haver a ação orientadora do educador. (MOURÃO; SOUZA, 2012, p. 31).

O Caderno de Educação Inclusiva aborda que é fundamental na atuação com esses alunos que o professor considere a diferença linguística e não a diferença biológica. Nesse sentido, é necessário ressaltar a importância e necessidade da atuação do professor bilíngue na educação infantil e nos anos

\footnotetext{
2 De acordo com o Decreto ${ }^{\circ} 5.626 / 2005$ (BRASIL, 2005) é considerado indivíduo surdo "[...] aquele que, por ter perda auditiva, compreende e interage com o mundo por meio de experiências visuais, manifestando sua cultura principalmente pelo uso da Libras [...]", e deficiente auditivo aquele que tem "[...] perda bilateral, parcial ou total de $41 \mathrm{~dB}$ (perda moderada) ou mais".
} 
iniciais do ensino fundamental e após a atuação do profissional intérprete da Língua Brasileira de Sinais (Libras) para que, assim, os alunos com deficiência auditiva ou com surdez elaborem os conceitos científicos dos conteúdos estudados, acessando os conhecimentos historicamente construídos. No entanto, o referido caderno nos permite saber que na maioria das vezes, na atuação com alunos surdos, "[...] a escrita do português, como se fosse a primeira língua, permanece como a maior preocupação da maioria dos professores." (BRASIL, 2014a, p. 32).

No AEE acontecem três momentos didáticos para os alunos surdos:

Trabalho em Libras - todos os conhecimentos dos diferentes conteúdos curriculares são explicados em Libras por um professor, sendo este preferencialmente surdo. [...] Ensino da Libras - os alunos terão aulas de Libras, favorecendo o conhecimento e a aquisição, principalmente de termos científicos. [...] Ensino da Língua Portuguesa - são trabalhadas as especificidades dessa língua para os alunos surdos. (BRASIL, 2014a, p. 35).

Dito de outro modo, o planejamento das aulas no AEE, a partir do trabalho em Libras, aborda os conteúdos trabalhados no ensino regular; no ensino da Libras, o professor desenvolverá trabalho de pesquisa sobre os termos científicos utilizados nas áreas do conhecimento; e no ensino da Língua Portuguesa é proporcionado o estudo e aprendizado do português, permitindo os alunos perceberem a estrutura da língua mediante diversas atividades.

Em síntese, a análise dos documentos evidencia que a proposta de formação do PNAIC considera e orienta a alfabetização de alunos com deficiência e o faz com base na teoria sócio-histórica.

No âmbito da teoria sócio-histórica, uma educação inclusiva deve ser fundamentalmente de caráter coletivo e considerar as especificidades dos estudantes. Por meio das interações sociais, e pela mediação semiótica, dá-se a reorganização do funcionamento psíquico de pessoas com e sem deficiência, favorecendo o desenvolvimento superior (BRASIL, 2012a, p. 8).

Com essa perspectiva, confirma-se a importância da formação continuada subsidiar aos professores, com base na teoria histórico-cultural, conhecimentos relacionados a uma formação inte- gral, que considere a diversidade de alunos que os professores irão encontrar nas salas de aula.

\section{Alfabetização e redução das desigualdades}

O tema das desigualdades escolares e sociais abre um leque enorme de discussão, pois está relacionado a diversos condicionantes. Por isso, entende-se que a deficiência por si só não é determinante das desigualdades, afinal, em uma sociedade que se pauta por padrões que normalizam as pessoas, certamente a condição física, intelectual e sensorial que não atende ao padrão estabelecido contribui para os processos de exclusão, mas é preciso atentar para os outros determinantes, como a classe social, raça, etnia, orientação sexual etc.

Como mencionado, a criação do PNAIC foi motivada pelos ideais de elevação do índice de alfabetização e de redução das desigualdades sociais. No Caderno formação de professores no Pacto Nacional pela Alfabetização na Idade Certa (BRASIL, 2012c, p. 20) é ressaltado que "[...] toda proposta de formação deve vir associada e fundamentada em uma proposta de sujeito, sociedade e escola baseada em valores e princípios de igualdade, justiça social e ampliação de oportunidades".

Diante dessa compreensão, é importante considerar que as políticas públicas e sociais, entre elas as educacionais, estão sendo elaboradas e lançadas a partir de um discurso que preconiza a busca da justiça social por meio da redução das desigualdades sociais, como é o caso do PNAIC, lançado com o objetivo de contribuir para a redução dessas desigualdades por meio da alfabetização. O discurso proferido pela presidenta Dilma Rousseff no lançamento do Pacto ilustra essa afirmação:

Nós sabemos sem sombra de dúvidas que um caminho, do ponto de vista de sua perenidade, mais que outros, tem o poder de assegurar o acesso das pessoas à igualdade de oportunidades: é a educação. Igualdade de oportunidades é uma situação em que, em um país, há garantia para todos os cidadãos tenham acesso a todas as oportunidades, seja qual for sua origem, gênero ou raça. (SOUSA; MEIRA, 2013, p. 01).

Nesse sentido, Arroyo (2010) ressalta que as políticas educacionais têm concentrado esforços para 
a superação das desigualdades. Até 1990 o esforço se concentrava basicamente no acesso da população à educação, mas, "Na década de 1990, o destaque passou a ser as desigualdades de acesso e de permanência [...]. Mais recentemente, se avança para as desigualdades de aprendizagem, de qualidade dos percursos" (ARROYO, 2010, p. 1.382). Ainda, o autor refere que as políticas e suas análises são empobrecidas quando se concentram nas "desigualdades intraescolares", porém "[...] se enriquecem na medida em que avançam na compreensão dos processos históricos de produção-reprodução das desigualdades sociais."(ARROYO, 2010, p. 1.381).

A formação continuada de professores proposta pelo PNAIC é apontada como uma das mais promissoras possibilidades de reverter o índice elevado de analfabetismo e o baixo desempenho escolar de grande parte dos alunos, configurando-se como uma estratégia para enfrentar o problema da distorção idade-série, fenômeno que indica de maneira muito evidente as desigualdades escolares. Para isso, as diferenças nos espaços educativos não podem ser transformadas em desigualdades, como historicamente tem acontecido com a educação das camadas populares brasileiras.

Como ressalta Arroyo (2010), precisa-se tomar o cuidado para que os diferentes não sejam tomados como desiguais. No que concerne à prática pedagógica com alunos com deficiência, muitas vezes é marcada pelo preconceito, construído pelo desconhecimento, o que transforma a diferença no ritmo de aprendizagem desses alunos, a necessidade de recursos e metodologias diferenciadas, dentre outros, em desigualdades no ensino e na aprendizagem. Assim, além de reproduzir as desigualdades sociais, o sistema educacional promove fatores de desigualdades que ultrapassam a simples reprodução das desigualdades encontradas na sociedade.

Todas as professoras entrevistadas afirmam que a alfabetização pode reduzir as desigualdades sociais, no entanto, algumas demonstraram dificuldades em expressar o que pensam sobre o tema e ainda mais quando ele é relacionado aos alunos com deficiência, tanto que diversas professoras solicitavam esclarecimento acerca da pergunta: A alfabetização contribui para a redução das desigualdades sociais? ou mesmo ficavam pensativas até conseguirem respondê-la.
Se todas as entrevistadas relacionam a alfabetização à redução das desigualdades, essa relação não foi feita de forma homogênea. A maioria das professoras compartilha de uma das compreensões que remete à ideia de que as desigualdades decorrem dos próprios indivíduos e, no caso da deficiência, da condição biológica, como assim demonstram as falas abaixo:

\section{A própria deficiência é uma desigualdade. (PRO- FESSORA 4).}

A desigualdade escolar vem de como cada um se apropria do conhecimento, né, eles não são iguais em atitudes e nem na aprendizagem, então isso também é uma desigualdade escolar, às vezes não demanda da prática do professor. (PROFESSORA 7).

Desigualdade pra mim é lá na minha turma ter alunos no terceiro ano que não se apropriaram da leitura e escrita, que mesmo que começaram a juntar as letrinhas, juntar as sílabas; é ter esses alunos que não conseguem avançar e ter aqueles que vão, andam. (PROFESSORA 8).

Para o convívio, sim, para o conhecimento, não. (PROFESSORA 11).

$\mathrm{Eu}$ acho que essa criança precisa saber o básico. (PROFESSORA 12).

Essas falas expressam a concepção das professoras sobre a aprendizagem, o desenvolvimento e as potencialidades dos alunos com deficiência, que nos parece estar apoiada numa abordagem de caráter biologizante, cujo enfoque organicista da deficiência permanece vivo no cotidiano de muitas práticas educativas, como bem expressa a Professora 4 ao naturalizar a desigualdade a partir da deficiência. Quando a Professora 12 refere que os alunos, por terem uma deficiência, precisam saber o básico, já expressa o sentido que atribui à alfabetização de alunos com deficiência, demonstrando a desigualdade face ao ensino, ou seja, embasada na compreensão de que por eles terem uma deficiência, não é necessário oportunizar todo o ensino, mas apenas o "básico". Como também a fala da Professora 11, a qual ressalta que a frequência dos alunos com deficiência na escola tem apenas o propósito da socialização e não da aprendizagem do conhecimento científico, objetivo principal da educação escolarizada. Por fim, as Professoras 7 
e 8 entendem que a aprendizagem é um processo que depende exclusivamente do aluno e que a maneira diferenciada como cada aluno se apropria do conhecimento é em si uma desigualdade, desconsiderando a prática de mediação do professor em sala de aula. Enfim, esses depoimentos apontam para práticas de classificação daqueles que, por serem diferentes, são tratados como desiguais, no contexto da escola e da sociedade.

Desse modo, compreende-se que embora tenha havido a democratização do acesso à educação escolar, os processos de seleção, exclusão, produção e reprodução das desigualdades escolares pelo sistema educacional permanecem vivos nas práticas educativas que, na sua maioria, ainda são permeadas pela discriminação e preconceito que inferioriza os alunos por terem uma deficiência. Assim, estes alunos ainda representam de forma peculiar a contradição entre a democratização do acesso à educação escolar e as concepções/processos de seleção que fundamentam as práticas educativas.

Ao contrário das falas anteriores, algumas professoras, como se evidencia nos trechos de entrevistas transcritos a seguir, apontam para a participação do contexto escolar e social na construção das desigualdades. Sendo assim, a Professora 1 considera que se ela não proporcionar aprendizagem aos alunos através do ensino, estará contribuindo para a desigualdade; a Professora 2 ressalta a importância dos professores se interessarem pelo avanço do aluno com deficiência; a Professora 9 acrescenta que a escola precisa se adequar às necessidades dos alunos; e a Professora 5 fala da importância da educação possibilitar aos alunos a construção de projeto de vida para, assim, diminuir as desigualdades sociais, embora não exclua em sua análise as condições objetivas de vida a que eles estão sujeitos:

Se eu não ensino e as crianças reprovam na escola, eu estou, sim, contribuindo para a exclusão, para a desigualdade, sim! Estou contribuindo para que ela não goste de vir pra escola. (PROFESSORA 1).

Quando ele é mesmo incluído, sim [a professora estava se referindo à questão da alfabetização diminuir ou não a desigualdade como proferido no discurso de lançamento do PNAIC], porque quando ele tá na escola e tem alguém pensando nele, valorizando as pequenas coisas que ele consegue avançar. [...] Faz a diferença a pessoa que está com o aluno incluído ter vontade que esse aluno avance, de ver ele progredindo, conquistando. (PROFESSORA 2).

Desigualdades sociais são muito mais marcadas pela falta de uma expectativa de vida, futuro, anseios, projetos, compreensão de mundo do que qualquer outra falta - isso não é regra. (PROFESSORA 5).

A escola contribui para a desigualdade social e educacional quando não trabalha as necessidades dos alunos, então essa criança que não está conseguindo acompanhar, ela vai ter um mundo diferente lá fora também, ela não se adapta à escola, nós não fazemos nada para que isso ocorra. (PROFESSORA 9).

Esse conjunto de falas relaciona o acesso à alfabetização à redução das desigualdades de modo a incluir os fatores escolares e sociais, porém isso não é feito de um modo crítico na medida em que não abordam que a deficiência ou qualquer outra diferença só será criadora de desigualdades devido a um determinado funcionamento do sistema de ensino no bojo do capitalismo, ou seja, das estruturas do sistema econômico, político e social que estão na base dos processos geradores da desigualdade no sistema educacional. O ensino, da forma como está estruturado, gera desigualdade, como é o caso de práticas pedagógicas homogêneas, currículo e avaliações padronizadas, seletividade das turmas por nível de conhecimento, dentre outros fatores que desconsideram as necessidades e expectativas dos alunos, tenham eles deficiência ou não.

Nessa direção, um dos documentos do PNAIC confirma que "[...] o aprendiz conquista o lugar social de um sujeito de direitos e a educação inclusiva viabiliza a efetivação da sua cidadania à medida que busca respeitar as peculiaridades de cada sujeito por meio de práticas de ensino acessíveis." (BRASIL, 2012b, p. 13). Para isso, as relações na escola não deveriam produzir e reproduzir as desigualdades. Ao contrário, através do currículo podem-se desconstruir os processos históricos de produção e reprodução das desigualdades a partir de práticas que possibilitem aos alunos a alfabetização, considerando suas diferenças.

Enfim, assim como as professoras, acredita-se que a alfabetização pode ser considerada uma estratégia para contribuir para a redução das desi- 
gualdades sociais e escolares, no sentido que a consideramos como elemento para a transformação da realidade, desde que levadas em conta as dimensões da produção e da reprodução das desigualdades sociais e escolares. Para tanto, a escola necessita desenvolver uma prática pedagógica mediadora da alfabetização como prática social partindo do contexto social, cultural e histórico dos alunos. No entanto, percebe-se que o sistema educacional e outros espaços educativos, da forma como estão estruturados, encontram dificuldades em trabalhar com a diversidade humana. Ou seja, as explicações das desigualdades não terminam quando discutidos e colocados em evidência os processos pedagógicos que transformam as diferenças em desigualdades escolares; é preciso atuar sobre eles de modo transformador.

Quando nos referimos à estrutura dos espaços educativos, não podemos nos esquecer que essa permeia as relações sociais e de poder estabelecidas fora dela, como as estruturas políticas, econômicas e sociais que privilegiam um padrão de norma e ordem; e a escola, muitas vezes, reproduz esse padrão através das práticas pedagógicas homogeneizadoras, descaracterizando a diversidade e diferenças nos/dos alunos que têm uma forma peculiar de demonstrar a sua linguagem oral, escrita e corporal. Isso se explicita em currículos e metodologias pensados de acordo com um padrão de ensino e aprendizagem que privilegia os alunos que aprendem do mesmo modo e no mesmo tempo.

Daí a necessidade de problematizarmos o termo "alfabetização na idade certa", se isso pressupor que há um tempo homogêneo para a alfabetização, embora essa problematização não deva ser utilizada para justificar o fato de que boa parcela de alunos terminem os três primeiros anos do ensino fundamental sem terem sido alfabetizados, e que o processo de alfabetização continue se estendendo, geralmente de modo precário, por anos escolares afora.

Desse modo, as diferenças que deveriam ser enriquecedoras do currículo são transformadas e reduzidas, pelos espaços educativos, em desigualdades. As capacidades dos alunos passam a ser avaliadas por provas e outros recursos que visam à seleção e à exclusão, sendo a responsabilidade do fracasso, na maioria das vezes, direcionada a eles e aos seus espaços familiares, sociais e culturais e/ ou aos professores.

Nessa direção, Arroyo (2011, p. 85) nos ajuda a refletir de forma crítica sobre a desigualdade escolar quando afirma:

Essa redução das desigualdades escolares aos alunos se acentua ao estarem chegando às escolas os/as filhos/as dos coletivos populares, os mais desiguais. Das políticas, da gestão e das análises se têm esperado que equacionem as desigualdades dos alunos e apontem mecanismos de sua correção. Nessa visão as desigualdades não são das escolas. Estas são apenas o lócus onde os desiguais se mostram desiguais.

A partir dessa compreensão, o sistema educacional transfere a responsabilidade das desigualdades para os sujeitos e omite o questionamento de que as desigualdades são proporcionadas pela sua própria estrutura, bem como as sociais, políticas educacionais e econômicas.

Com base nessa compreensão, é importante considerar que as desigualdades são resultantes de um conjunto de dimensões variadas intra e extraescolares. A dimensão intraescolar envolve as questões político-pedagógicas das unidades e sistemas escolares, as condições físicas, os recursos pedagógicos, os programas de formação de professores e a valorização financeira e cultural dos professores, bem como as políticas de acesso, permanência e avaliação dos alunos, dentre outras; já a extraescolar envolve as macroquestões relativas à distribuição de renda, à garantia da educação com qualidade como direito social, o papel do Estado, as políticas educacionais etc.

Diante disso, entende-se que não é suficiente propor políticas educacionais objetivando a redução da desigualdade social sem que as bases sociais, políticas e econômicas sejam reestruturadas para atenderem as necessidades exigidas na construção de uma sociedade mais justa e igualitária. Contudo, a formação continuada proporcionada pelo PNAIC pode ser considerada uma estratégia potencializadora de mudanças nas práticas pedagógicas, que historicamente têm transformado as diferenças em desigualdades. No entanto, é preciso considerar que a qualidade da ação educativa na alfabetização, especificamente com alunos com deficiência, como constatamos nas falas das professoras, está 
atrelada ao sentido que elas atribuem à formação continuada, vislumbrando-a como possibilidade ou não de ressignificar a sua prática alfabetizadora.

A partir dessa visão, faz-se necessário pensarmos a efetivação dessa formação para além dos conteúdos específicos e para além dos espaços acadêmicos e escolares. $\mathrm{O}$ cotidiano se configura como espaço permeado de saberes e conhecimentos, sendo estes produzidos pelos sujeitos, que são constituídos no conjunto das relações sociais que, muitas vezes, estão pautadas em práticas excludentes, descomprometidas com a ética a com a alteridade. Assim sendo, o padrão de normalidade é ditado pela sociedade e os espaços educativos muitas vezes o reproduzem nas suas práticas.

As falas de algumas professoras demonstram que, mesmo com os avanços tanto em relação ao sentido atribuído à deficiência quanto nas ações pedagógicas, elas ainda encontram dificuldades de planejar e desenvolver uma prática alfabetizadora que leve em conta que, na sala de aula, encontrarão alunos com diversas necessidades educacionais e, assim, reproduzem através das suas ações mecanismos que engendram relações de poder excludentes na sociedade.

Nessa perspectiva, Stoer e Cortesão (1999 apud MOREIRA; CANDAU, 2007, p. 31, grifo do autor) defendem a superação do "daltonismo cultural":

Elaborar currículos culturalmente orientados demanda uma nova postura, por parte da comunidade escolar, de abertura às distintas manifestações culturais. Faz-se indispensável superar o 'daltonismo cultural', ainda bastante presente nas escolas. O/a professor/a 'daltônico cultural'é aquele que não valoriza o 'arco-íris de culturas' que encontra nas salas de aulas e com que precisa trabalhar, não tirando, portanto, proveito da riqueza que marca esse panorama. É aquele que vê todos os estudantes como idênticos, não levando em conta a necessidade de estabelecer diferenças nas atividades pedagógicas que promove.

Compreende-se que a formação integral expressa o modo do professor e do aluno conceberem e intervirem no mundo. Diante disso, a formação poderá desenvolver práticas que contribuam para os professores eliminarem preconceitos e discriminações que, muitas vezes, expressam e sustentam as desigualdades escolares e sociais. Sendo assim, as estratégias de formação de professores proporcio- nadas pelo PNAIC precisam estar fundamentadas em teorias e práticas sociais que, além de respeitar e considerar as diferenças como enriquecedoras para a mediação de conhecimentos na sala de aula, contribuam significativamente para a superação de ações discriminatórias e preconceituosas por meio da produção de conhecimentos socialmente mediados.

\section{Considerações finais}

Constata-se nos documentos da formação continuada proposta pelo PNAIC que este programa pretende atender as necessidades educacionais de todos os alunos, visto que são enfatizadas as práticas pedagógicas pautadas na diversidade e nas diferenças, dentre elas, os alunos com deficiência. Ainda mais, os documentos enfatizam a necessidade de conhecimentos específicos sobre cada deficiência para que o professor possa organizar suas aulas de modo que atendam, de acordo com a funcionalidade de cada aluno, as necessidades de recursos, metodologias e estratégias de aprendizagem. Então, quando perguntamos sobre o modo como os documentos orientam a alfabetização de alunos com deficiência, não partimos do pressuposto de que os conhecimentos teóricos desta área devam ser trabalhados de maneira distinta dos demais alunos, e sim trabalhados de forma que se tornem acessíveis a eles.

Mediante a análise dos documentos, afirmamos que o PNAIC pode ser considerado o programa de formação continuada na área de alfabetização mais abrangente já desenvolvido em nosso país. A possibilidade de cada município brasileiro e de todos os professores dos três primeiros anos do ensino fundamental aderirem à formação e o envolvimento das universidades, das secretarias de educação e escolas tornam este programa o de mais larga escala proporcionado até o momento. Isso implica na sua relevância como política educacional e seus impactos na educação e na sociedade em geral, visto que a alfabetização é importante para o processo de escolarização de todos os brasileiros e a escolarização bem-sucedida ser um dos elementos importantes para o desenvolvimento do país, visto de uma perspectiva emancipatória 
e igualitária. Perspectiva esta que não prescinde de outras políticas (sociais e econômicas) que, de forma articulada com as políticas educacionais, promovam mudanças nas condições de vida dos segmentos populacionais que, muitas vezes, ainda não usufruem da escola e de outros espaços sociais como possibilidades de humanização, como é o caso das pessoas com deficiência.

As professoras entrevistadas consideram que a alfabetização contribui para a redução das desigualdades escolares e sociais a partir de compreensões diversas. Uma delas remete à ideia de que as desigualdades decorrem dos próprios indivíduos e, no caso da deficiência, da condição biológica; e outra compreensão aponta para a participação do contexto escolar e social na construção das desigualdades. No entanto, como se afirmou, isso não é feito de um modo crítico, tomando por base a ideia de justiça social.

Os achados e análises deste estudo nos permitem remeter à posição teórica, ética e política referente à formação de professores integralmente orientada, tendo como base a teoria histórico-cultural, por entendermos que esta possibilita o redimensionamento da prática pedagógica do professor alfabetizador no sentido da inclusão de todos e, de modo específico, dos alunos com deficiência, e da contribuição para a diminuição das desigualdades produzidas pelo sistema educacional.
Por fim, os resultados e discussões apresentados neste estudo poderão contribuir para a efetivação de formação continuada de professores alfabetizadores, integralmente orientados, tendo como fundamento a aprendizagem de todos os alunos. Desse modo, entendemos que as bases empíricas fornecidas pela pesquisa científica, como a nossa, precisam ser consideradas no processo de planejamento da formação e na tomada de decisão política no campo educacional.

Desse modo, a formação poderá subsidiar uma reflexão sobre as teorias que embasam a prática alfabetizadora, a fim de contribuir com as condições necessárias para que, mediante estas teorias e a práxis pedagógica, os professores possam reconstruir e ressignificar as suas concepções. Assim, a educação escolar, especificamente a alfabetização, poderá oportunizar práticas de ampliação da participação dos sujeitos com deficiência na vida social.

A análise crítica de políticas educacionais, como apontado na introdução, neste caso o Pacto Nacional pela Alfabetização na Idade Certa (uma política colocada em prática por meio de um programa), reafirma a compreensão de Ball e Mainardes (2011, p. 14) de que "Elas não são [...] fixas e imutáveis e podem ser sujeitas a interpretações e traduções e compreendidas como respostas a problemas da prática. As políticas estão sempre em algum tipo de fluxo, no processo de se tornarem algo mais".

\section{REFERÊNCIAS}

ARROYO, Miguel Gonzalez. Políticas educacionais e desigualdades: à procura de novos significados. Educação \& Sociedade, Campinas, v. 31, n. 113, p. 1381-1416, out./dez. 2010.

. Políticas educacionais, igualdade e diferenças. Revista Brasileira de Política e Administração da Educação (RBPAE), Porto Alegre, v. 27, n. 1, p. 83-94, jan./abr. 2011.

AURELIANO, Francisca Edilma Braga Soares. O Programa Pró-letramento e a formação de alfabetizadores: repercussões nas concepções e práticas de professores cursistas. 2012. 179 f. Dissertação (Mestrado em Educação) - Universidade Federal do Rio Grande do Norte, Natal, 2012.

BALL, Stephen; MAINARDES, Jefferson. Introdução. In: lemas. São Paulo: Cortez, 2011. p. 11-18.

(Org.). Políticas educacionais: questões e di-

BRASIL. Presidência da República. Decreto n. 5.626, de 22 de dezembro de 2005. Regulamenta a Lei n. 10.436, de 24 de abril de 2002, que dispõe sobre a Língua Brasileira de Sinais - Libras, e o art. 18 da Lei n. 10.098, de 19 de dezembro de 2000. Brasília, DF, 2005.

. Ministério da Educação. Plano de Desenvolvimento da Educação. Brasília, DF, 2007.

Ministério da Educação. Marcos político-legais da educação especial na perspectiva da educação inclusiva. Brasília, DF, 2010. 
. Ministério da Educação. Pacto Nacional pela Alfabetização na Idade Certa - caderno de educação especial: a alfabetização de crianças com deficiência: uma proposta inclusiva. Brasília, DF, 2012a.

Ministério da Educação. Pacto Nacional pela Alfabetização na Idade Certa - currículo na alfabetização: concepções e princípios: ano 1: unidade 1. Brasília, DF, 2012b.

Ministério da Educação. Pacto Nacional pela Alfabetização na Idade Certa: formação de professores no pacto nacional pela alfabetização na idade certa. Brasília, DF, 2012c.

Ministério da Educação. Pacto Nacional pela Alfabetização na Idade Certa: formação do professor alfabetizador: caderno de apresentação. Brasília, DF, 2012d.

Ministério da Educação. Pacto Nacional pela Alfabetização na Idade Certa: educação inclusiva: alfabetização matemática. Brasília, DF, 2014a.

Presidência da República. Lei n. 13.005, de 25 de junho de 2014. Aprova o Plano Nacional de Educação - PNE e dá outras providências. Brasília, DF, 2014b.

Ministério da Educação. Política Nacional de Educação Especial na

Perspectiva da Educação Inclusiva. Brasília, DF, 2008. Disponível em: < http://portal.mec.gov.br/index. php?option=com_docman\&view=download\&alias=16690-politica-nacional-de-educacao-especial-na-perspectiva-da-educacao-inclusiva-05122014\&Itemid=30192>. Acesso em: 29 out. 2015.

CAVALCANTE, Tícia Cassiany Ferro. A pessoa com deficiência motora frente ao processo de alfabetização. In: BRASIL. Ministério da Educação. Caderno de Educação Especial: a alfabetização de crianças com deficiência: uma proposta inclusiva. Brasília: MEC/SEB, 2012. p. 10-14.

DECLARAÇÃO DE SALAMANCA. Sobre princípios, políticas e práticas na área das necessidades educativas especiais. Brasília, DF: MEC, 1994. Disponível em: <http://portal.mec.gov.br/seesp/arquivos/pdf/salamanca.pdf>. Acesso em: 29 out. 2015.

LUCACHINSKI, Elci Schroeder. Pacto nacional pela alfabetização na idade certa: a formação de professores para a prática alfabetizadora com alunos com deficiência. 2015. 144 f. Dissertação (Mestrado em Educação) Universidade Comunitária da Região de Chapecó, Chapecó, SC, 2015.

LÜDKE, Menga; ANDRÉ, Marli Eliza Dalmazo Afonso de. Pesquisa em educação: abordagens qualitativas. São Paulo: EPU, 1986.

MINAYO, Maria Cecília de Souza. O desafio do conhecimento: pesquisa qualitativa em saúde. 11. ed. São Paulo: Hucitec, 2008.

MOREIRA, Antonio Flávio Barbosa; CANDAU, Vera Maria. Princípios para a construção de currículos multiculturalmente orientados. In: BEAUCHAMP, Jeanete; PAGEL, Sandra Denise; NASCIMENTO, Aricélia Ribeiro do (Org.). Indagações sobre currículo: currículo, conhecimento e cultura. Brasília, DF: MEC/SEB, 2007. p. 17-48.

MOURÃO, Carlos Antonio Fontenele; SOUZA, Vilma Pastos de Andrade. A alfabetização da pessoa surda: desafios e possibilidades. In: BRASIL. Secretaria de Educação Básica. Ministério da Educação. Diretoria de Apoio à Gestão Educacional. Caderno de Educação Especial: a alfabetização de crianças com deficiência: uma proposta inclusiva. Brasília, DF: MEC/SEB, 2012. p. 28-32.

SEAL, Ana Gabriela de Souza. Estratégias de ensino na alfabetização da pessoa cega e com baixa visão. In: BRASIL. Ministério da Educação. Caderno de Educação Especial: a alfabetização de crianças com deficiência: uma proposta inclusiva. Brasília, DF: MEC/SEB, 2012. p. 21-27.

SOARES, Magda. Alfabetização e letramento. São Paulo: Cortez, 2003.

SOUSA, Kilma Wayne Silva de; MEIRA, Vanderléia Lucena. Pacto Nacional pela Alfabetização na Idade Certa (PNAIC). Pet Pedagogia, Goiânia, 15 abr. 2013. Disponível em: <http://pedagogiaufcg.blogspot.com.br/2013/04/ pacto-nacional-pela-alfabetizacao-na.html >. Acesso em: 29 out. 2015.

VERONEZI, Rafaela Júlia Batista; DAMASCENO, Benito Pereira; FERNANDES, Yvens Barbosa. Funções psicológicas superiores: origem social e natureza mediada. Revista de Ciências Médicas, Campinas, v. 14, n. 6, p. 537-541, nov./dez. 2005. 
VYGOTSKY, Lev Semenovich. Fundamentos de defectología. 2. ed. Havana: Editorial Pueblo y Educación, 1995. (Obras Completas, tomo 5).

A construção do pensamento e da linguagem. São Paulo: Martins Fontes, 2009.

Recebido em: 30.11 .2015

Aprovado em: 12.02 .2016 